\title{
Liposomal curcumin inhibits hypoxia-induced angiogenesis after transcatheter arterial embolization in VX2 rabbit liver tumors
}

This article was published in the following Dove Press journal:

OncoTargets and Therapy

15 September 2015

Number of times this article has been viewed

\section{Feng Dai ${ }^{1,2}$ \\ Xiuming Zhang ${ }^{3}$ \\ Wenrong Shen ${ }^{3}$ \\ Jun Chen ${ }^{4}$ \\ Liucheng Liu ${ }^{5}$ \\ Gejun $\mathrm{Gao}^{6}$}

'The First College of Clinical Medicine, Nanjing University of Chinese Medicine, ${ }^{2}$ Department of Interventional Radiology, The Second Hospital of Nanjing, Medical School, Southeast University, ${ }^{3}$ Department of Radiology, ${ }^{4}$ Department of Interventional Radiology, Jiangsu Province Tumor Hospital, ${ }^{5}$ Department of Pharmacy, Jiangsu Aosakang Pharmaceutical Co. Ltd, ${ }^{6}$ Department of Radiology, Jiangsu Province Hospital of TCM, Nanjing University of Chinese Medicine, Nanjing, People's Republic of China
Correspondence: Gejun Gao Department of Radiology, Affiliated Hospital of Nanjing University of Chinese Medicine, I 55 Hanzhong Road, Nanjing 210029, People's Republic of China Tel +86258362 6060 Email gejun_gao@163.com
Purpose: The purpose of the study is to investigate the inhibition of hypoxia-induced angiogenesis after embolization in VX2 rabbit liver tumors by liposomal curcumin.

Materials and methods: A total of 54 VX2 rabbits were divided into three groups, and each group had three subgroups according to the sacrifice time. The animals in the control group $(n=18)$ underwent sham embolization. Transcatheter arterial embolization (TAE)-treated group $(n=18)$ animals underwent embolization with lipiodol $(0.1 \mathrm{~mL} / \mathrm{kg}$ body weight $)$ and $90-180 \mu \mathrm{m}$ polyvinyl alcohol (PVA) particles. Liposomal curcumin TAE-treated group $(n=18)$ animals underwent embolization with liposomal curcumin $(20 \mathrm{mg} / \mathrm{kg}$ body weight $)$ mixed with lipiodol $(0.1 \mathrm{~mL} / \mathrm{kg}$ body weight) and 90-180 $\mu \mathrm{m}$ PVA particles. After embolization, the animals in each subgroup were sacrificed at 6 hours, 24 hours, and 3 days, and the tumor samples were collected. Immunohistochemical staining was performed to evaluate expression of hypoxia-inducible factor- $1 \alpha$ (HIF-1 $\alpha$ ) and vascular endothelial growth factor (VEGF) proteins, and microvessel density (MVD). Real-time polymerase chain reaction was performed to examine VEGF mRNA levels. Results: The levels of HIF- $1 \alpha$ and VEGF, and MVD in tumors of liposomal curcumin TAEtreated group were significantly decreased compared to the TAE-treated group $(P<0.05)$. There was a slight decrease in tumor size in the liposomal curcumin TAE-treated group at third-day time points compared to the TAE-treated group; the difference was not statistically significant $(P>0.05)$. The HIF-1 $\alpha$ protein correlated considerably with VEGF mRNA $(r=0.705, P=0.001)$ and protein $(r=0.655, P=0.003)$, and $\operatorname{MVD}(r=0.521, P=0.027)$. A significant correlation between VEGF protein and MVD was noted as well $(r=0.519, P=0.027)$.

Conclusion: Liposomal curcumin downregulates HIF-1 $\alpha$ protein levels and inhibits hypoxiainduced angiogenesis after embolization in VX2 rabbit liver tumors.

Keywords: hypoxia-inducible factor-1 $\alpha$, angiogenesis, embolization, liver tumor

\section{Introduction}

Hepatocellular carcinoma (HCC) is the fifth most common cancer worldwide and the third most common cause of cancer mortality. ${ }^{1}$ Surgical procedures such as liver resection or transplantation are the mainstay of treatment, but unfortunately, only $10 \%-15 \%$ of patients with HCC can be effectively treated with curative surgery. ${ }^{2}$ Based on the fact that hepatic malignant lesions receive most (90\%-100\%) of their blood supply from the hepatic artery, injecting embolization agents into the tumor-feeding vessel may induce tumor ischemic necrosis. ${ }^{3}$ Therefore, transcatheter arterial embolization (TAE) has been widely performed as palliative treatment for nonsurgical HCC, which can suppress tumor growth and prolong the survival of HCC patients. ${ }^{4}$

Although embolization of liver tumors can suppress the tumor growth early in its course, the medium- and long-term efficacy of the procedure is not satisfactory. ${ }^{5}$ The major 
factor limiting its therapeutic efficacy is hypoxia-induced angiogenesis after TAE. Incomplete embolization and complexity of tumor-feeding vessels may result in residual tumors in hypoxia microenvironment. Hypoxia-inducible factor-1 (HIF-1) may be a key transcription factor that mediates adaptive cell response to hypoxia, which composes of HIF-1 $\alpha$ subunit and HIF-1 $\beta$ subunit (also known as ARNT). In the absence of oxygen, HIF-1 binds to hypoxia-response elements (HREs), thereby activating the expression of numerous HREs, such as the pro-angiogenic growth factor vascular endothelial growth factor (VEGF). ${ }^{6}$ Previous studies have demonstrated that HIF- $1 \alpha$ protein levels were significantly increased in the TAE-treated tumors compared with the control tumors. Meanwhile, the levels of HIF-1 $\alpha$ were positively correlated with the levels of VEGF and microvessel density (MVD) in the residual tumor. ${ }^{7,8}$ These results suggest HIF-1 $\alpha$ is induced in liver tumors after TAE and involved in the activation of the TAE-associated tumor angiogenesis.

Currently, more VEGF receptor tyrosine kinase inhibitors, such as imatinib, sorafenib, and cediranib, are well studied to suppress angiogenesis in cancer treatment. However, these inhibitors damage not only tumor vessels but also healthy vessels and result in severe side effects such as hypertension, proteinuria, and leukopenia. In addition, administration of VEGF blockers alone can aggravate tumor hypoxia and worsen malignancy to invasive and metastatic form. ${ }^{9,10}$ Therefore, researchers increasingly focus their attention on new effective anti-angiogenesis agents and other therapeutic targets.

Curcumin is considered to be a safe material and has been widely used in traditional Chinese medicine for the treatment of inflammation and other diseases. ${ }^{11}$ Bae et al showed that curcumin strongly suppressed the HIF-1 $\alpha$ protein level and functional activity of angiogenesis under hypoxia conditions in HepG2 HCC cells. ${ }^{12}$ Although curcumin shows good drug characteristic as an anti-inflammatory and anticancer agent, the poor bioavailability limits its clinical utility. ${ }^{13}$ To avoid these limitations, a new liposomal formulation of curcumin was developed, which showed good effect in inhibiting growth and invasion in human cancers. ${ }^{14}$ Therefore, the purpose of this study was to use liposomal curcumin for blocking HIF-1 $\alpha$-mediated angiogenesis, and to examine its suppressing effect on the expression of HIF-1 $\alpha$ and angiogenesis after TAE in the VX2 rabbit liver tumors.

\section{Materials and methods Liposomal curcumin}

Curcumin and dichloromethane were obtained from Sinopharm Chemical (Beijing, People's Republic of China).
Soybean phosphatidylcholine (SPC) and cholesterol (CHOL) were purchased from Nippon Fine Chemical (Chuo-Ku, Japan).

The preparation process involved several steps. First, the lipids and curcumin (SPC:CHOL:curcumin, 15:5:1, w/w/w) were dissolved and mixed in dichloromethane to assure a homogeneous mixture of the solution. Second, the solvent was removed to yield a film as soon as the lipids and curcumin were thoroughly mixed in dichloromethane. The solution was transferred to containers and then frozen by placing the containers on a block of dry ice-alcohol bath. Third, the frozen lipid cake was placed on a vacuum pump and lyophilized until dried (1-3 days depending on volume). Fourth, hydration of the dry film/cake was accomplished simply by adding phosphate-buffered saline $(\mathrm{pH}$ 7.0) solution to the container of dry film and agitating at a temperature of $45^{\circ} \mathrm{C}$. Lastly, the particles were downsized by extrusion. A lipid suspension is forced through a polycarbonate filter with a defined pore size to yield particles. ${ }^{15}$ The suspensions were disrupted by filtering through $200 \mathrm{~nm}$ and $100 \mathrm{~nm}$ polycarbonate filters. Extrusion through filters with $100 \mathrm{~nm}$ pores typically yielded large, unilamellar vesicles with a mean diameter of 100-150 nm. The sample was stored at $2^{\circ} \mathrm{C}-8^{\circ} \mathrm{C}$ and warmed up to room temperature just before use.

Liposome size and zeta potential were measured using a Malvern Zetasizer Nano-series (Malvern Instruments Nano-ZS, Malvern, UK). Transmission electron microscopy images were taken using a Hitachi H-7650 transmission electron microscope (Hitachi, Tokyo, Japan) operating at an accelerating voltage of $80 \mathrm{kV}$.

\section{VX2 rabbit tumor model}

New Zealand white rabbits $(2.5-3.0 \mathrm{~kg})$ were obtained from the Experiment Animal Center of Southeast University (Nanjing, People's Republic of China), and animal experiments were approved by the Animal Care Committee of the Nanjing University of Chinese Medicine.

The VX2 strain was maintained by successive transplantation into the hindlimbs of carrier rabbits. For implantation of the VX2 tumor into the liver, the tumor was first harvested from the carrier rabbit and minced in $0.9 \%$ normal saline solution. The recipient rabbits were anesthetized via intravenous injection of pentobarbital sodium $(30 \mathrm{mg} / \mathrm{kg}$; Abbott Laboratories, North Chicago, IL, USA). Then, these rabbits were exposed through a sub-xiphoid abdominal incision, and fresh tumor tissues measuring $1 \mathrm{~mm} \times 1 \mathrm{~mm} \times 1 \mathrm{~mm}$ were embedded $10 \mathrm{~mm}$ deep into the left liver lobe. ${ }^{16}$ 
The abdominal wall was subsequently closed, and ampicillin ( $150 \mathrm{mg} / \mathrm{kg}$ body weight) was injected into the muscles for the management of infection. All VX2 rabbits were given normal feedings for 18-20 days, and then, they were examined with computed tomography (CT; SOMATOM Emotion, Siemens Medical Solutions, Germany), which showed the tumors reaching $2 \mathrm{~cm}$ in diameter.

In the present study, we focus on the effects of the liposomal curcumin suppressing the expression of HIF-1 $\alpha$ and angiogenesis in liver tumors after embolization; thus, the group treated with liposomal curcumin only was excluded. The VX2 rabbits were divided into three groups. Group 1 (control group, $\mathrm{n}=18$ ) animals underwent sham embolization with $0.9 \%$ normal saline solution. Group 2 (TAE-treated group, $\mathrm{n}=18$ ) animals underwent embolization with lipiodol (UltraFludie, Guerbet, France) and 90-180 $\mu \mathrm{m}$ polyvinyl alcohol (PVA) particles (Cook, Bloomington, IN, USA). Group 3 (liposomal curcumin TAE-treated group, $n=18$ ) animals underwent embolization with liposomal curcumin $(20 \mathrm{mg} / \mathrm{kg}$ body weight) mixed with lipiodol and 90-180 $\mu \mathrm{m}$ PVA particles. Based on the time of sacrifice, the animals in each group were then divided into three subgroups: subgroup $1 \quad(n=6)$, 6 hours after experimental intervention; subgroup 2 ( $n=6)$, 24 hours after experimental intervention; and subgroup 3 $(n=6), 3$ days after experimental intervention.

\section{Interventional procedures}

After CT scan, TAE was immediately performed in VX2 models under digital subtraction angiography (Angiostar Plus; Siemens, Germany). The right femoral artery was exposed and accessed through open puncture with an $18 \mathrm{G} \times 2$ in needle (SURFLO FLASH; Terumo, Japan), and then, a 2.2 F micro-catheter (ASAHI INTECC, Japan) was introduced through the plastic sheath of the $18-\mathrm{G}$ needle into the abdominal aorta. Based on angiography by injecting contract media (Omnipaque 350, GE Healthcare, People's Republic of China), the micro-catheter was advanced to super-select the common hepatic, proper hepatic, and tumor's blood supply artery in sequence. Lipiodol $(0.1 \mathrm{~mL} / \mathrm{kg}$ body weight) was slowly administered under guidance with realtime fluoroscopy. As lipiodol flow became slow, $0.1 \mathrm{~mL}$ of PVA particles mixture was carefully injected. The embolization ended as the antegrade blood flow was completely static. For the control group, $2 \mathrm{~mL}$ of $0.9 \%$ normal saline solution was injected instead of the lipiodol and PVA particles. For the liposomal curcumin TAE-treated group, liposomal curcumin (20 mg/kg body weight) mixed with lipiodol $(0.1 \mathrm{~mL} / \mathrm{kg}$ body weight) was slowly administered, and then, embolization was done with PVA particles. All VX2 models were given normal feeding and antibiotics after TAE.

\section{Immunohistochemistry of HIF- I $\alpha$,VEGF, and CD3 I}

Six hours, 24 hours, and 3 days after embolization, the diameter of the tumor was measured by CT (SOMATOM Emotion, Siemens Medical Solutions). All VX2 rabbits were sacrificed by intravenous administration of $20 \mathrm{~mL}$ air. Tumor and peritumoral liver tissues were collected. Part of the specimen was flash frozen at $-70^{\circ} \mathrm{C}$ for real-time polymerase chain reaction (RT-PCR), and the rest was fixed in $10 \%$ buffered neutral formalin and embedded in paraffin. Four-micron-thick slices were cut and processed for histological staining.

For immunohistochemical detection of HIF-1 $\alpha$, VEGF, and CD31, specimens were incubated overnight at $4{ }^{\circ} \mathrm{C}$ with mouse anti-HIF-1 $\alpha$ (dilution, 1:50; Thermo Fisher Scientific, Waltham, MA, USA), mouse anti-VEGF (dilution, 1:50; EMD Millipore, Billerica, MA, USA), and mouse anti-CD31 (dilution, 1:20; Dako, Glostrup, Denmark) monoclonal antibodies, respectively. The sections were then incubated with secondary antibody for 30 minutes at room temperature, and binding reactions were visualized using 3,3'-diaminobenzidine substrate. Nuclei were lightly counterstained with hematoxylin.

Immunohistochemical staining was evaluated by two pathologists in a blind manner. All slides were examined under a light microscope throughout the entire section. Discrepancies were resolved by the conference microscope. The levels of HIF-1 $\alpha$ protein were classified as follows: 0 , no staining; $1+$, nuclear staining in less than $1 \%$ of cells; $2+$, nuclear staining in $1 \%-10 \%$ of cells and/or with weak cytoplasmic staining; $3+$, nuclear staining in 10\%-50\% of cells and/or with distinct cytoplasmic staining; and 4+, nuclear staining in more than $50 \%$ of cells and/or with strong cytoplasmic staining. ${ }^{17}$ VEGF protein levels were graded on a $0-4$ scale: 0 , no staining; $1+$, cytoplasmic staining in less than $10 \%$ of cells; $2+$, cytoplasmic staining in $10 \%-50 \%$ of cells; and $3+$, cytoplasmic staining in more than $50 \%$ of cells. ${ }^{18}$ The percentage of positive staining cells was measured by Image Process System (HPIAS-1000, Qianping Image Technology Company Limited, Wuhan, People's Republic of China). MVD was evaluated by means of the counting method introduced by Weidner et al. ${ }^{19}$ The tumor sections were scanned at low magnification $(\times 40, \times 100)$ to find the areas that showed the most intense vascularization (host spots), and then, individual microvessels were counted in five different high-magnification fields $(\times 400)$. 
Any CD31-stained endothelial cell or cell cluster that was clearly separated from adjacent tissue elements was counted as a single countable microvessel. The final MVD was the mean value obtained from the counts of the five fields.

\section{RT-PCR analysis of VEGF mRNA}

Total RNA was isolated from the samples with TRIzol reagent (Invitrogen 15596-026). cDNA was synthesized from $1 \mu \mathrm{g}$ of total RNA with the First-Strand cDNA Synthesis Kit (Thermo Fisher K1622). Oligonucleotide primers for polymerase chain reaction (PCR) were designed as follows: VEGF: sense primer 5'-CATGGCAGAAGAAGGAGACA-3' and antisense primer 5'-GGAAGATGTCCACCAAGGTC-3'; and GAPDH: sense primer 5'-CGCCTGGGAAAGCTGCTAA-3' and antisense primer 5'-CGACCTGGTCCTCG GTGTAG-3'. PCRs were carried out by SYBR Green Real-time PCR master mix (Toyobo, Osaka, Japan). The expression of VEGF mRNA was quantified relatively by the $2^{-\Delta \Delta C t}$ method.

\section{Statistical analyses}

Statistical analyses were carried out by SPSS version 17.0 (SPSS, Chicago, IL, USA). Measured data were expressed as mean \pm standard deviation. The Kruskal-Wallis $H$ test was used to compare the levels of HIF-1 $\alpha$ and VEGF proteins at three time points among the groups. Single-factor variance analysis and least significance difference test or Tamhane's multiple comparisons were used to compare the RT-PCR expression of VEGF mRNA and MVD. The Spearman's rank

A
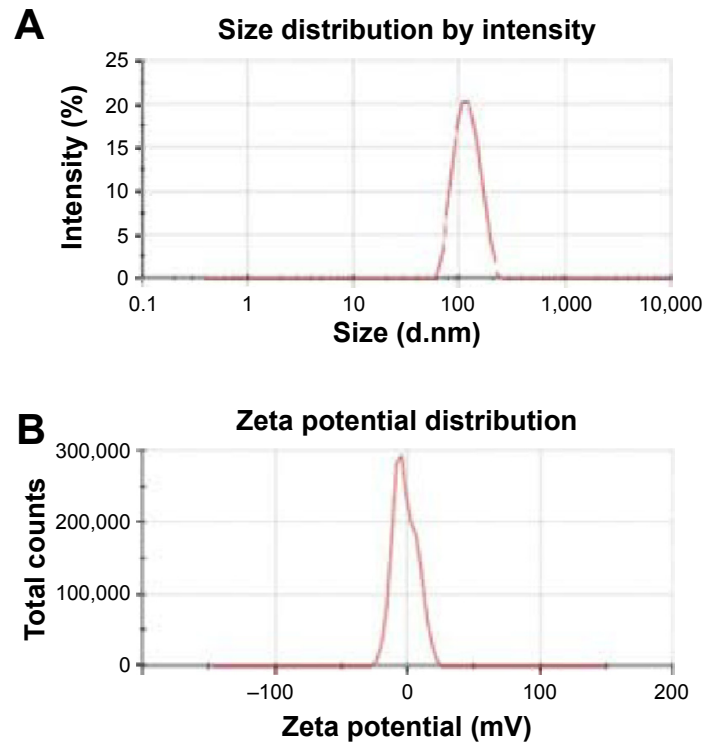

correlation coefficient test was used to assess the correlation of HIF-1 $\alpha$ protein with VEGF mRNA and protein and MVD. A $P$-value $<0.05$ was considered to be statistically significant.

\section{Results}

\section{Liposomal curcumin}

The formulation of liposomal curcumin was characterized by particle size, zeta potential, and liposomal morphology. The average particle size of the liposomal curcumin was $118.2 \pm 0.91 \mathrm{~nm}$. The zeta potential or total charge on the surface of the liposomes was $-1.66 \pm 0.14 \mathrm{mV}$. Surface morphology of the liposomes presented a spherical shape in standard electronic modules (Figure 1).

\section{VX2 rabbit tumor model and change in tumor size}

CT images showed that solitary VX2 tumors were grown in the left liver lobe of each model (Figure 2A). All targeted tumors were successfully catheterized, and then, the tumorfeeding vessels were obstructed (Figure 2B and C). Figure 2D shows iodized oil accumulation in the tumor margin and gas density after necrosis in embolized tumor center.

In the control group, the diameter of the tumor revealed a trend of obvious growth from $20.15 \pm 0.16 \mathrm{~mm}$ to $24.53 \pm 0.15 \mathrm{~mm}$ after sham embolization. The tumor size slightly decreased in the liposomal curcumin TAE-treated group compared to the TAEtreated group, and the difference was not statistically significant $(P>0.05)$ on the third day after embolization (Figure 3).

\section{C}

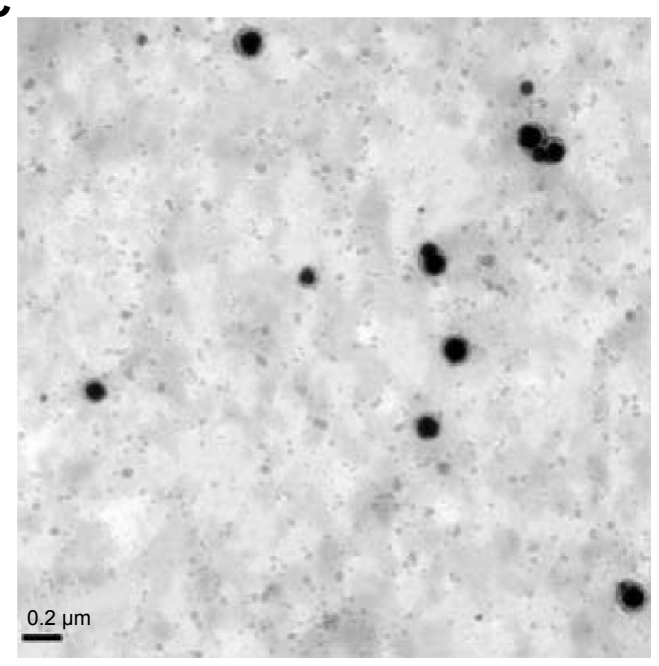

Figure I The formulation of liposomal curcumin.

Notes: (A) Particle size of liposomal curcumin (I $18.2 \pm 0.91 \mathrm{~nm})$. (B) Zeta potential of liposomal curcumin $(-1.66 \pm 0.14 \mathrm{mV})$. (C) Surface morphology of liposomal curcumin by TEM.

Abbreviation: TEM, transmission electron microscopy. 

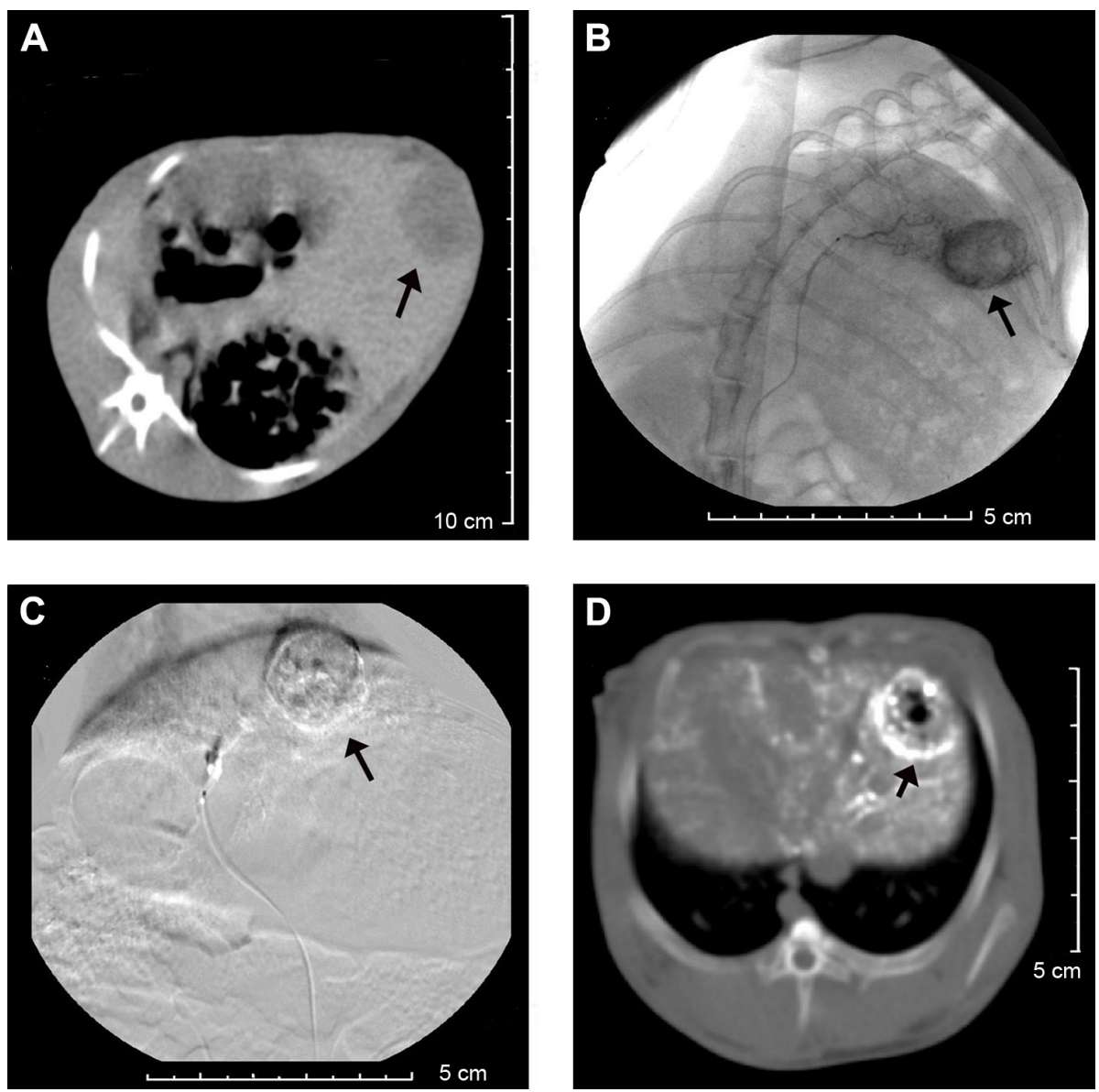

Figure 2 The images of the tumor.

Notes: (A) CT showed a low-intensity VX2 tumor (arrow) in the left liver lobe. (B) Selective left hepatic artery angiogram before TAE, showing a hyper-vascular tumor (arrow) in the left liver lobe. (C) Selective angiogram after TAE demonstrated no feeding vessel to tumor (arrow). (D) CT showed iodized oil accumulation in the tumor margin (arrow) and gas density after necrosis in embolized tumor center.

Abbreviations: CT, computed tomography; TAE, transcatheter arterial embolization.

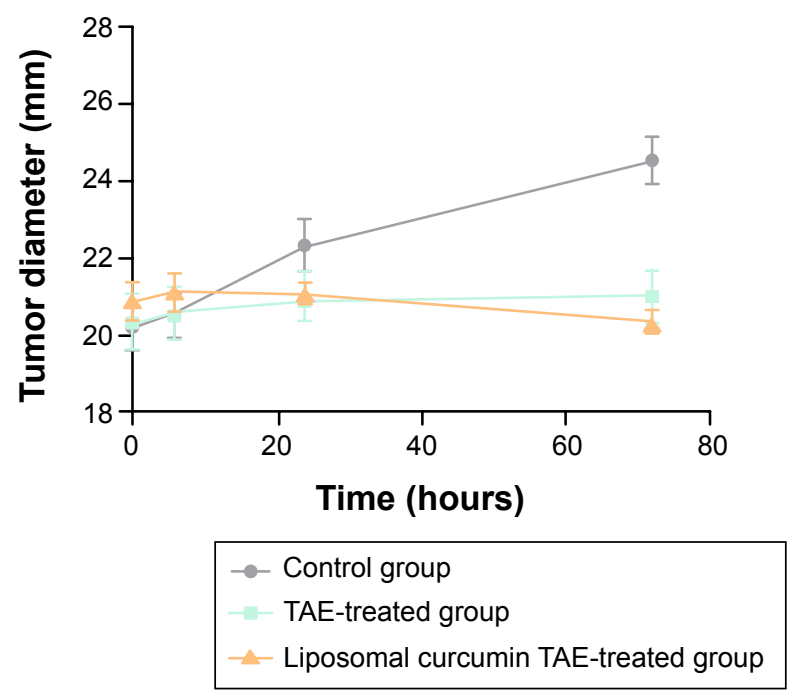

Figure 3 Change in tumor size.

Notes: Line graph showed the diameter of the tumor at different time points after treatment. The tumor size had no statistical significance $(P>0.05)$ in the liposomal TAE-treated group compared to the TAE-treated group. Abbreviation: TAE, transcatheter arterial embolization.

\section{Expression of HIF-I $\alpha$ protein}

Representative positive HIF-1 $\alpha$ staining was noted in both cytoplasm and nucleus of viable tumor cells. In the TAEtreated group, HIF-1 $\alpha$-positive cells were highly presented at the residual tumors near necrosis of the tumor peripheral zone. In contrast, the liposomal curcumin TAE-treated group showed scattered positive cells at the residual tumors (Figure 4). The levels of HIF-1 $\alpha$ protein in the liposomal TAE-treated group significantly decreased compared to the TAE-treated group at three time points $(P<0.05)$. However, no significant difference was found in HIF-1 $\alpha$ levels between the control group and the liposomal curcumin TAE-treated group $(P>0.05)$ (Table 1).

\section{Expressions of VEGF protein and mRNA, and MVD}

For VEGF, positivity was indicated as a cytoplasmic expression. Compared to the other groups, representative 
A

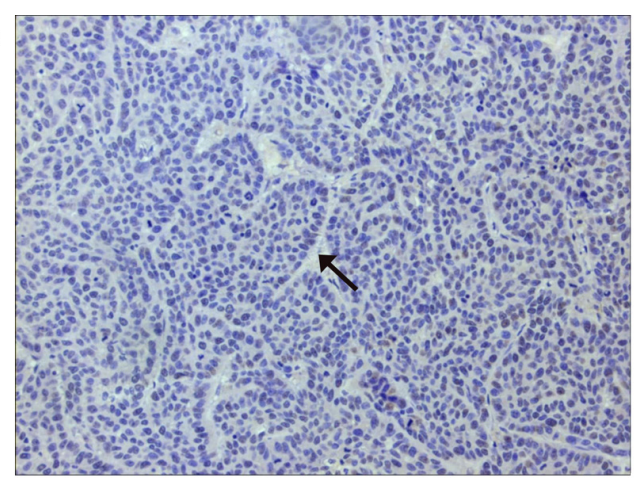

C

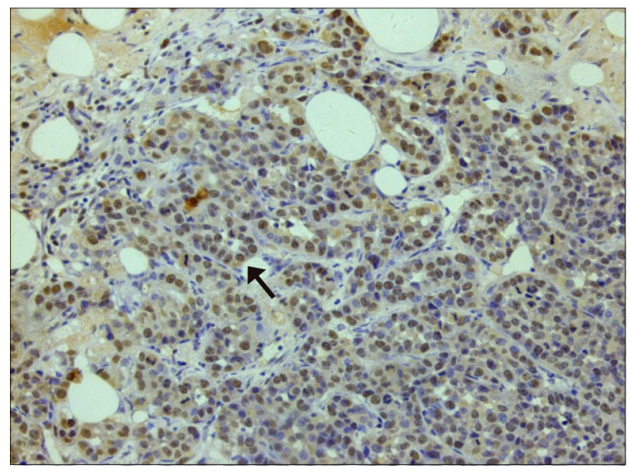

E

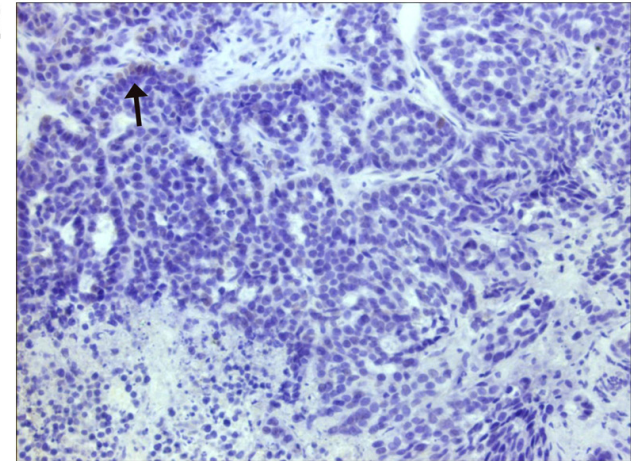

B

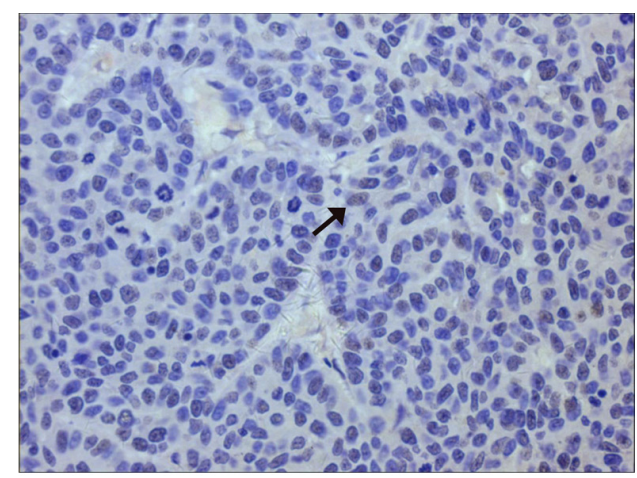

D

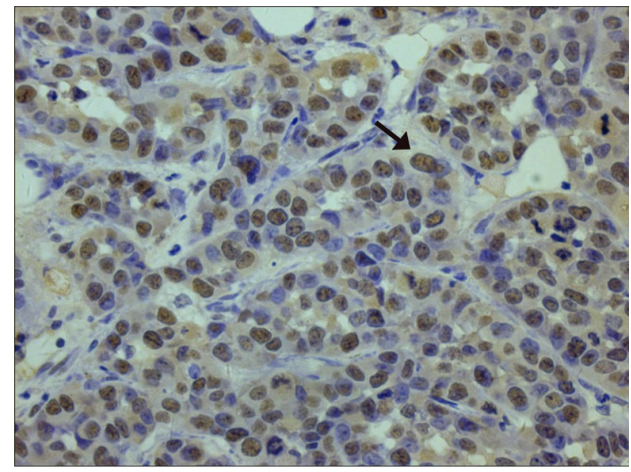

$\mathbf{F}$

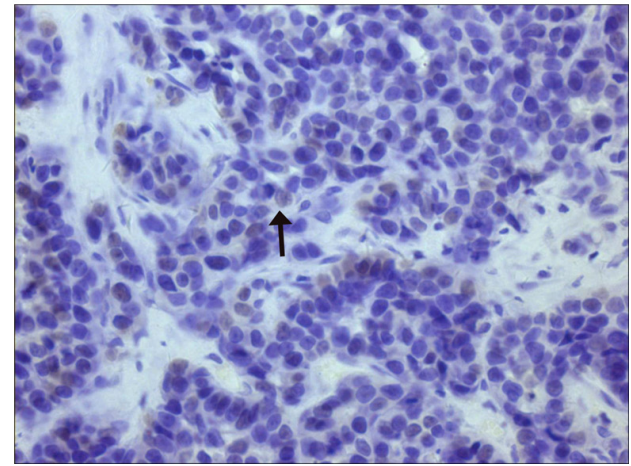

Figure 4 Immunohistochemical staining of $\mathrm{HIF}-\mathrm{I} \alpha$.

Notes: (A and B) Control group: tumors showed scattered HIF-I $\alpha$-positive cells (arrows), which demonstrated a I+staining (A: $\times 200$, B: $\times 400)$. (C and D) TAE-treated Group: much more HIF-I $\alpha$-positive cells (arrows) presented in residual tumors after embolization, which demonstrated a 4+ staining $(\mathbf{C}: \times 200$, D: $\times 400)$. (E and F) Liposomal curcumin TAE-treated group: HIF-I $\alpha$-positive tumor cells decreased compared with TAE-treated group, which demonstrated a I+ staining (arrows) (E: $\times 200$, F: $\times 400)$.

Abbreviations: HIF-I $\alpha$, hypoxia-inducible factor-I $\alpha$; TAE, transcatheter arterial embolization.

Table I Expression of HIF-I $\alpha$ protein in three groups

\begin{tabular}{|c|c|c|c|c|c|c|c|c|c|c|}
\hline \multirow[t]{2}{*}{ Time } & \multirow[t]{2}{*}{ Group } & \multicolumn{5}{|c|}{ HIF-I $\alpha$ protein levels } & \multicolumn{4}{|l|}{$P$-value } \\
\hline & & 0 & $\mathbf{I +}$ & $2+$ & $3+$ & $4+$ & $\begin{array}{l}\text { All three } \\
\text { groups }\end{array}$ & $\begin{array}{l}\text { Group I vs } \\
\text { group } 2\end{array}$ & $\begin{array}{l}\text { Group I vs } \\
\text { group } 3\end{array}$ & $\begin{array}{l}\text { Group } 2 \text { vs } \\
\text { group } 3\end{array}$ \\
\hline \multirow[t]{3}{*}{6 hours } & I $(n=6)$ & 3 & 2 & I & & & & & & \\
\hline & $2(n=6)$ & & & I & 3 & 2 & 0.003 & 0.004 & 0.665 & 0.004 \\
\hline & $3(n=6)$ & 2 & 3 & I & & & & & & \\
\hline \multirow[t]{3}{*}{24 hours } & I $(n=6)$ & 3 & 2 & I & & & & & & \\
\hline & $2(n=6)$ & & & & 4 & 2 & 0.002 & 0.003 & 0.652 & 0.003 \\
\hline & $3(n=6)$ & I & 4 & I & & & & & & \\
\hline \multirow[t]{3}{*}{3 days } & I $(n=6)$ & 4 & I & I & & & & & & \\
\hline & $2(n=6)$ & & & I & 4 & 1 & 0.003 & 0.004 & 0.652 & 0.004 \\
\hline & $3(n=6)$ & 3 & 2 & I & & & & & & \\
\hline
\end{tabular}

Notes: Group I means control group, group 2 means TAE-treated group, and group 3 means liposomal curcumin TAE-treated group. P, statistical comparison between groups.

Abbreviations: HIF-I $\alpha$, hypoxia-inducible factor-I $\alpha$; TAE, transcatheter arterial embolization. 

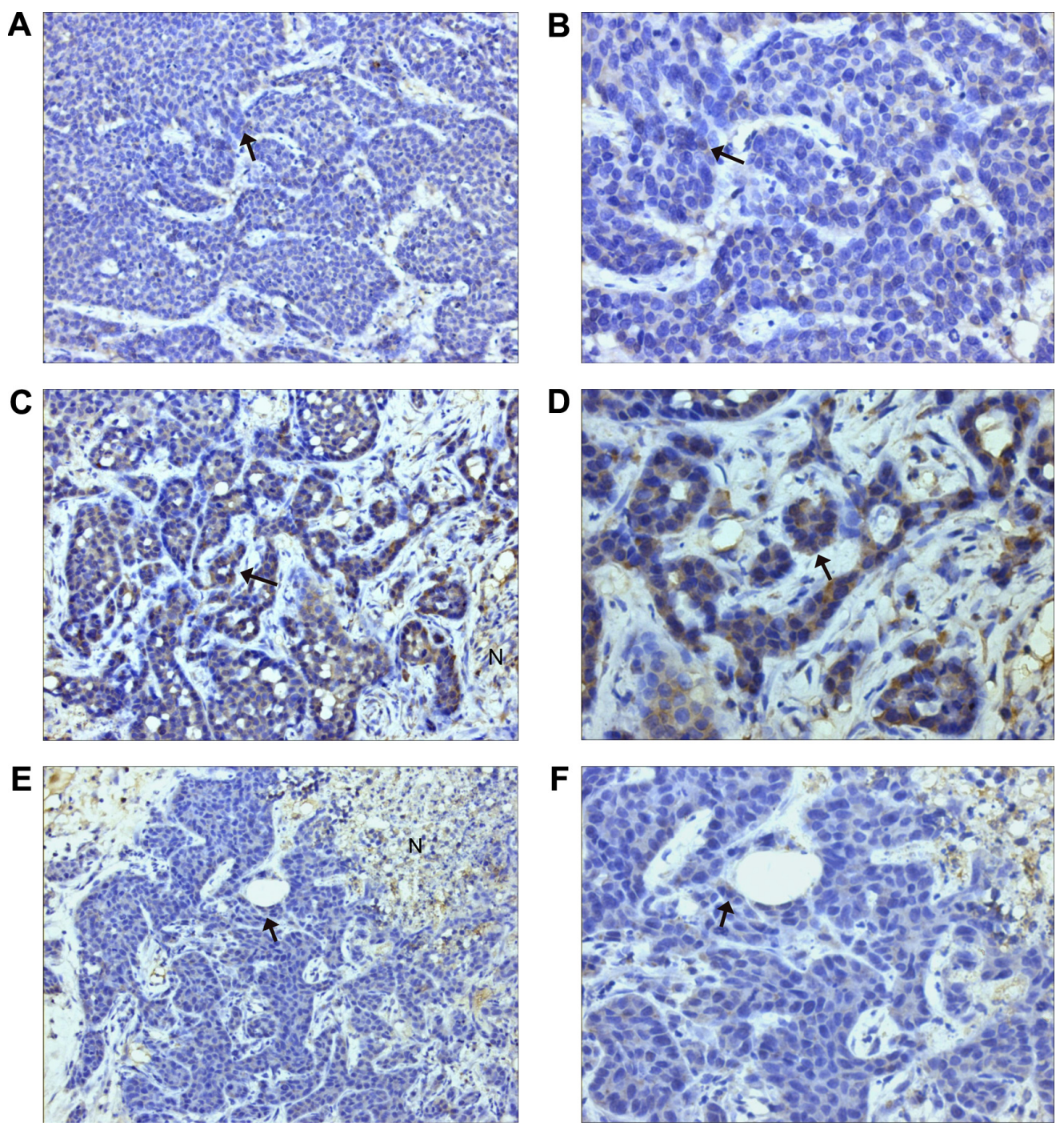

Figure 5 Immunohistochemical staining of VEGF.

Notes: (A and B) Control group: tumors showed scattered VEGF-positive cells (arrows), $(\mathbf{A}: \times 200, \mathbf{B}: \times 400)$. (C and D) TAE-treated group: much more VEGF-positive expression showed in the tumors, which demonstrated a 3+ staining (arrows) (C: $\times 200, \mathbf{D}: \times 400)$. (E and F) Liposomal curcumin TAE-treated group: VEGF-positive tumor cells decreased compared with TAE group, which demonstrated a I+staining (arrows) (E: $\times 200, \mathbf{F}: \times 400$ ).

Abbreviations: VEGF, vascular endothelial growth factor; TAE, transcatheter arterial embolization; N, necrosis.

VEGF-positive cells were highly presented in the residual tumors near necrosis zone in the TAE-treated group (Figure 5). The levels of VEGF mRNA and protein substantially decreased and had a statistical difference at three time points $(P<0.05)$ in the liposomal curcumin TAE-treated tumors compared with the TAE-treated tumors (Figure 6 and Table 2). However, no significant difference was found in VEGF levels between the control group and the liposomal curcumin TAE-treated group $(P>0.05)$ (Table 2$)$.

Microvessels were heterogeneously distributed in the tumors, and the most intense vascularization was observed at the invading edge of tumor margins and in adjacent normal hepatic sinusoids in the TAE-treated group in Figure 7. The line graph in Figure 8 shows that the mean MVD presented

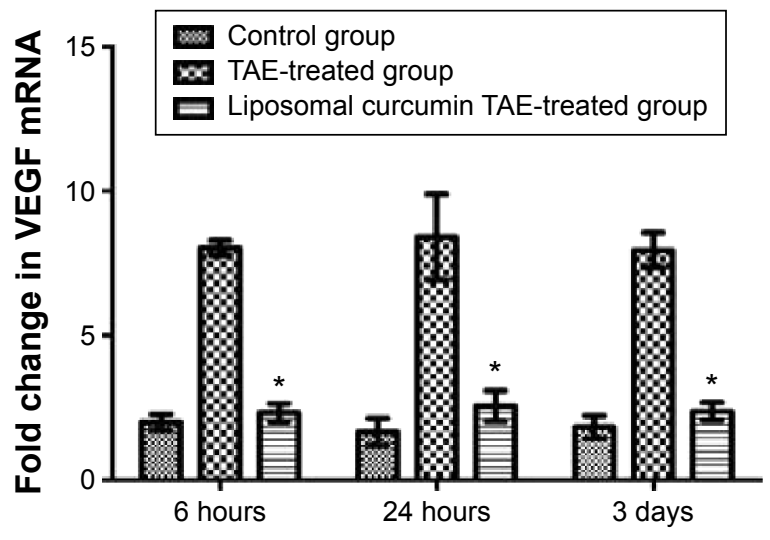

Figure 6 Fold change in VEGF mRNA relative to $\beta$-actin.

Note: Compared to TAE-treated group, a significant decrease and statistical difference in liposomal curcumin TAE-treated group is indicated by “*”.

Abbreviations: VEGF, vascular endothelial growth factor; TAE, transcatheter arterial embolization. 
Table 2 Expression of VEGF protein in three groups

\begin{tabular}{|c|c|c|c|c|c|c|c|c|c|}
\hline \multirow[t]{2}{*}{ Time } & \multirow[t]{2}{*}{ Group } & \multicolumn{4}{|c|}{ VEGF protein levels } & \multicolumn{4}{|l|}{$P$-value } \\
\hline & & 0 & $\mathbf{I}+$ & $2+$ & $3+$ & $\begin{array}{l}\text { All three } \\
\text { groups }\end{array}$ & $\begin{array}{l}\text { Group I vs } \\
\text { group } 2\end{array}$ & $\begin{array}{l}\text { Group I vs } \\
\text { group } 3\end{array}$ & $\begin{array}{l}\text { Group } 2 \text { vs } \\
\text { group } 3\end{array}$ \\
\hline \multirow[t]{3}{*}{6 hours } & I $(n=6)$ & 3 & 3 & & & & & & \\
\hline & $2(n=6)$ & & & 3 & 3 & 0.004 & 0.003 & 0.299 & 0.012 \\
\hline & $3(n=6)$ & 2 & 2 & 2 & & & & & \\
\hline \multirow[t]{3}{*}{24 hours } & I $(n=6)$ & 4 & 2 & & & & & & \\
\hline & $2(n=6)$ & & & 2 & 4 & 0.002 & 0.003 & 0.212 & 0.005 \\
\hline & $3(n=6)$ & 2 & 3 & 1 & & & & & \\
\hline \multirow[t]{3}{*}{3 days } & I $(n=6)$ & 3 & 3 & & & & & & \\
\hline & $2(n=6)$ & & & 4 & 2 & 0.004 & 0.003 & 0.789 & 0.007 \\
\hline & $3(n=6)$ & 3 & 2 & I & & & & & \\
\hline
\end{tabular}

Notes: Group I means control group, group 2 means TAE-treated group, and group 3 means liposomal curcumin TAE-treated group. P, statistical comparison between three groups.

Abbreviations: VEGF, vascular endothelial growth factor; TAE, transcatheter arterial embolization.

A

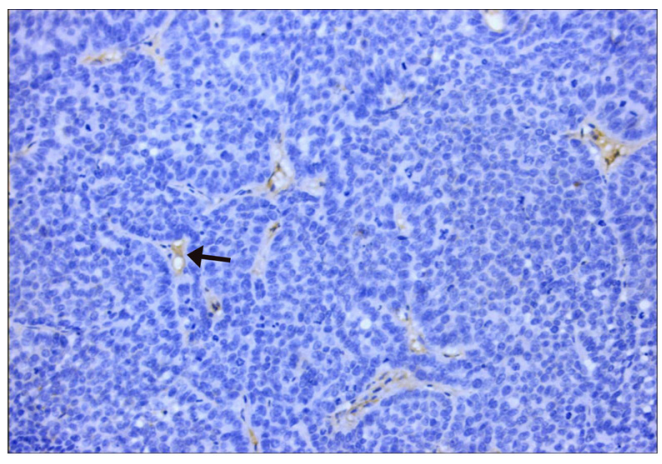

C

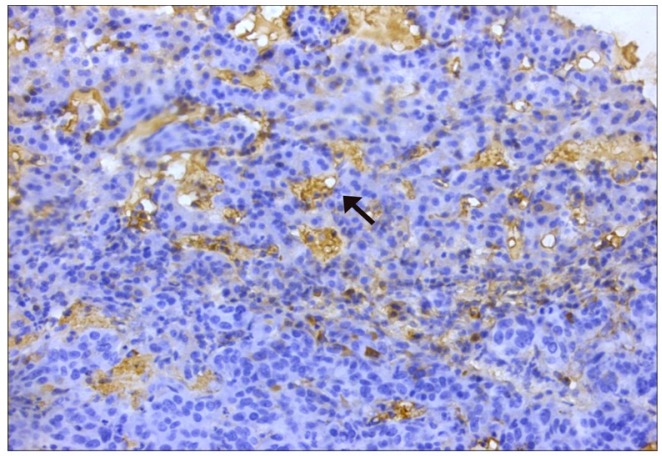

E

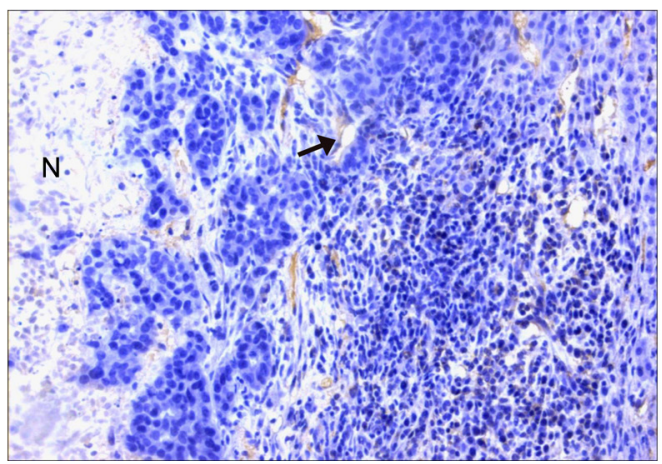

B
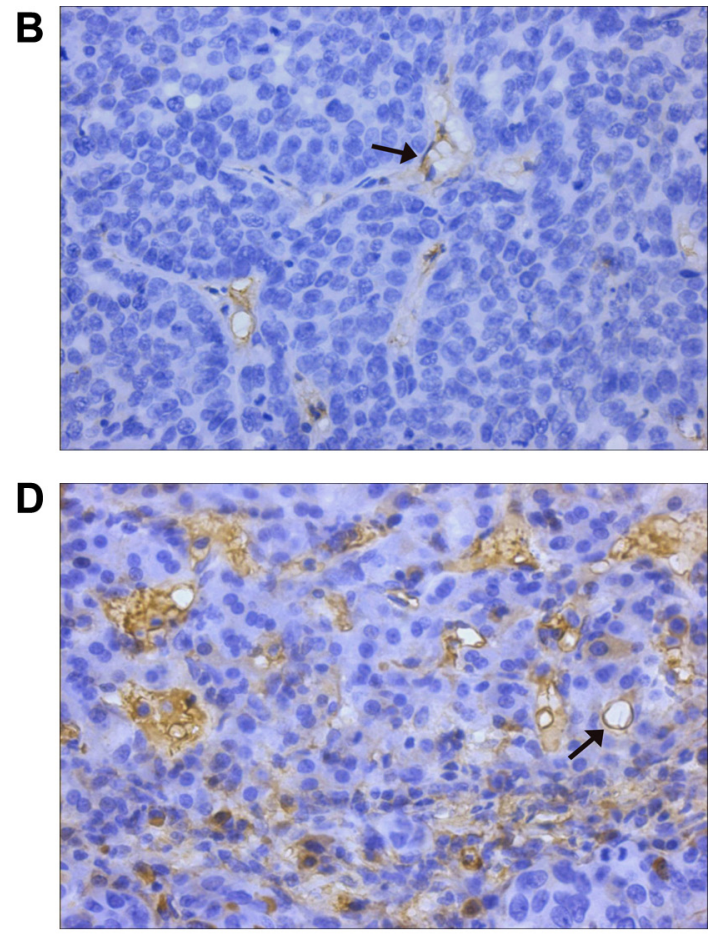

$\mathbf{F}$

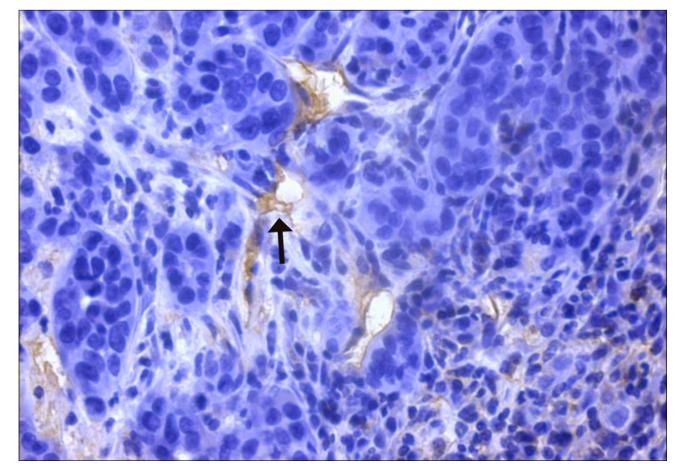

Figure 7 Immunohistochemical staining of CD31.

Notes: (A and B) Control group: some microvessels are observed in the tumor (arrows) $(\mathbf{A}: \times 200, \mathbf{B}: \times 400)$. (C and D) TAE-treated group: abundant microvessels are found at the invading edge of tumor margins (arrows) (C: $\times 200$, D: $\times 400)$. (E and F) Liposomal curcumin TAE-treated group: microvessels decreased significantly (arrows) (E: $\times 200$, F: $\times 400)$.

Abbreviations: TAE, transcatheter arterial embolization; N, necrosis. 

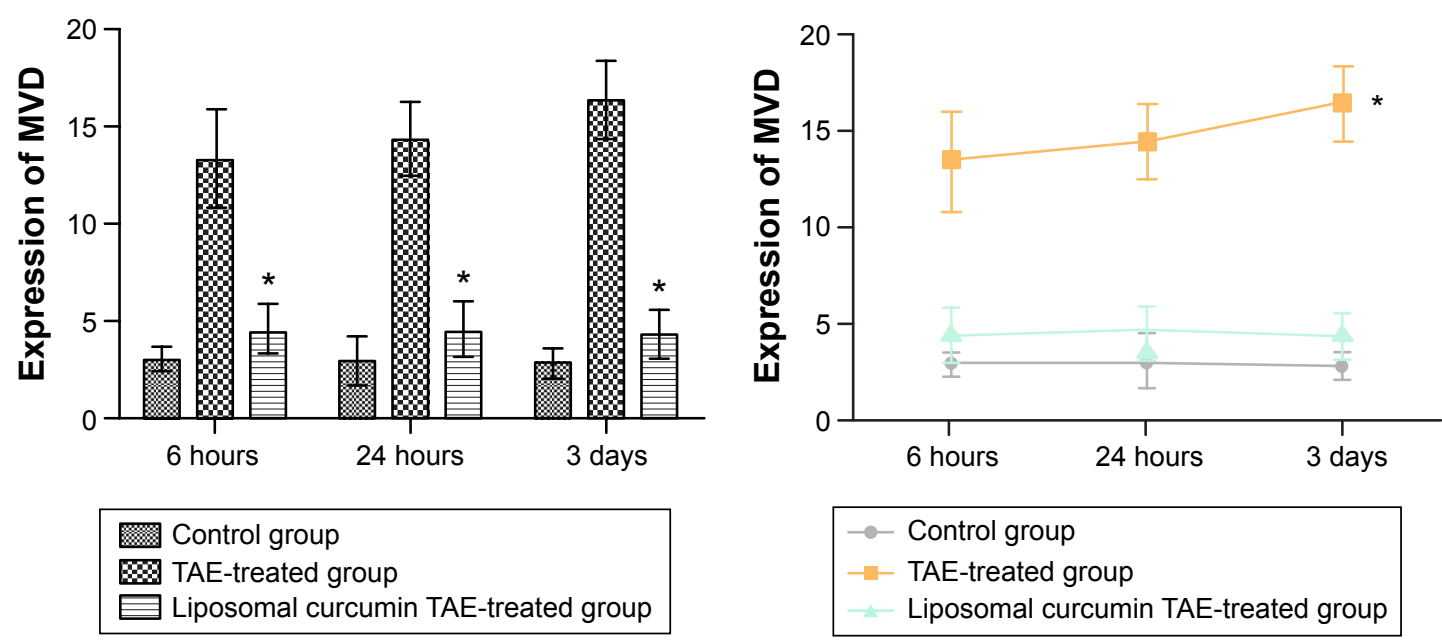

Figure 8 Expression of MVD.

Notes: In the column graph, compared to the TAE-treated group, a significant decrease and statistical difference in the liposomal curcumin TAE-treated group is indicated by "*”. In the line graph, "*” shows that the mean MVD significantly increased and had the statistical difference between 6 hours and 3 days in the TAE-treated group. Abbreviations: TAE, transcatheter arterial embolization; MVD, microvessel density.

an obvious rising $(P<0.05)$ from 6 hours to 3 days in the TAE-treated group. Meanwhile, the column graph revealed that the mean MVD had significantly decreased $(P<0.05)$ in the liposomal curcumin TAE-treated group compared with the TAE-treated group. Although the liposomal curcumin TAE-treated group tumors showed a small increase in mean MVD compared with the control group, the difference did not reach statistical significance $(P>0.05)$.

In Table 3, Spearman's rank correlation analysis showed that HIF-1 $\alpha$ protein significantly correlated with VEGF mRNA $(r=0.705, P=0.001)$ and protein $(r=0.655, P=0.003)$, and MVD ( $r=0.521, P=0.027)$ after embolization in VX2 rabbits. A significant correlation between VEGF protein and MVD was noted as well ( $r=0.519, P=0.027)$.

\section{Discussion}

The purpose of embolization is to interrupt blood flow to the tumors so as to induce ischemic necrosis and tumor hypoxia. Therefore, hypoxia-induced angiogenesis in residual tumors is considered as the major limiting factor after TAE. At present, a variety of angiogenesis targets and inhibitors have been widely studied. VEGF and Angiopoietin 2 (Ang 2) are the most popular therapeutic targets, which are expressed on cancer cells by hypoxia stimulation. VEGF and its receptor control the early steps triggering the angiogenic cascade. Ang 2 is expressed during vascular remodeling, which destabilizes the vascular integrity and allows VEGF to stimulate endothelial cells. ${ }^{20}$ More tyrosine kinase inhibitors, such as sorafenib, cediranib, and imatinib, target the VEGF-mediated angiogenesis and suppress it. However, the side effects and anti-VEGF therapy alone aggravating tumor hypoxia may not be sufficient to control tumor growth. Therefore, upstream HIF-1 may be an effective therapeutic target in inhibiting angiogenesis after embolization.

Curcumin is a major traditional Chinese medicine, which has been widely used in anti-inflammation and other diseases. In 1996, Bethesda first reported that curcumin could regulate angiogenesis in the wound. ${ }^{21}$ Since then, numerous groups have shown that curcumin modulates angiogenesis both in vitro and in vivo. ${ }^{22}$ Previous studies demonstrated that curcumin not only interfered with the HIF-1 $\alpha$ protein generation and/or stabilization system but also downregulated HIF- $1 \alpha$ at the mRNA level, suggesting that different mechanisms of action mediate the overall inhibitory role of curcumin on HIF-1 $\alpha$ production. In addition, curcumin was not able to suppress HIF-1 by downregulating ARNT. ${ }^{12,23}$ Therefore, curcumin may be an effective HIF-1 $\alpha$ target drug in inhibiting angiogenesis after TAE. However, curcumin is

Table 3 Correlation of HIF-I $\alpha$ protein with three factors

\begin{tabular}{|c|c|c|c|c|c|c|}
\hline & \multicolumn{2}{|c|}{ VEGF mRNA } & \multicolumn{2}{|c|}{ VEGF protein } & \multicolumn{2}{|l|}{ MVD } \\
\hline & $r$ & $P$-value & $r$ & $P$-value & $r$ & $P$-value \\
\hline HIF-I $\alpha$ protein & 0.705 & 0.001 & 0.655 & 0.003 & 0.521 & 0.027 \\
\hline
\end{tabular}

Abbreviations: HIF-I $\alpha$, hypoxia-inducible factor-I $\alpha$; VEGF, vascular endothelial growth factor; MVD, microvessel density. 
limited in its clinical utility because of its poor bioavailability. To overcome this limitation, the liposomal formation of curcumin has recently been developed. Previous studies have shown that this formulation has anti-proliferative and anti-angiogenesis effects equal to or greater than that of free curcumin against human cancer. ${ }^{24}$

In our study, the average particle size of liposomal curcumin was $118.2 \pm 0.91 \mathrm{~nm}$, and the zeta potential charge was $-1.66 \pm 0.14 \mathrm{mV}$, which were thought to have good physical properties. Previous studies showed that $20 \mathrm{mg} / \mathrm{kg}$ liposomal curcumin was the optimal dose for intravenous administration in rat and dog models, which had greater inhibition of tumor growth. ${ }^{25}$ We chose $20 \mathrm{mg} / \mathrm{kg}$ body weight, which is theoretically sufficient for HIF-1 $\alpha$ inhibition in VX2 rabbits via the hepatic artery. To achieve effective rival delivery to targeted tumor beds, the mixture of liposomal curcumin and lipiodol was used. Moreover, subsequent embolization with PVA particles not only prolongs contact time of liposomal curcumin with tumor cells by reducing the drug washout but also allows the liposomal curcumin to penetrate into tumor cells with greater ease. ${ }^{26}$

The HIF-1 $\alpha$ protein levels overexpressed in early stage after TAE have been investigated in clinical and animal liver tumor models. ${ }^{27}$ In this study, the level of HIF-1 $\alpha$ protein significantly increased in early stage in the TAE-treated group compared with the control group. Meanwhile, more HIF-1 $\alpha$ positive cells expressed in residual tumor cells close to the necrosis in the TAE-treated group. The results also showed a statistically significant increase in levels of VEGF mRNA and protein at three time points in the TAE-treated group compared with the control group. The line graph revealed that the mean MVD began to rise at 6 hours and reached a maximum at 3 days after embolization in the TAE-treated group in Figure 8. The relationships between HIF-1 $\alpha$ and angiogenesis factors are proven in Table 3 . It is possible that HIF- $1 \alpha$ plays an important role in the regulation of TAEassociated angiogenesis. This result suggested that hypoxia change induced the HIF- $1 \alpha$ protein overexpression in residual tumors after $\mathrm{TAE}$, which may be a therapeutic target inhibiting hypoxia-induced angiogenesis in liver tumors.

However, the distribution of MVD staining expression was different from those of positive HIF-1 $\alpha$ and VEGF expression. The most intense MVD was distributed at the invading edge of tumor margins and adjacent normal hepatic sinusoids after embolization in the TAE-treated group in Figure 7. These results may explain that VEGF stimulates tumor angiogenesis in a paracrine fashion, which stimulates and promotes residual tumor or atypia tissues near normal liver tissues to get more blood supply and recurrence through angiogenesis, and make up for the tumor ischemia and necrosis after embolization.

In this study, we used liposomal curcumin as an HIF-1 $\alpha$ protein inhibitor and explored its inhibition effect on HIF-1 $\alpha$ expression and HIF-1 $\alpha$-mediated angiogenesis after embolization in liver tumors. Tables 1 and 2 and Figure 6 show that the level of HIF-1 $\alpha$ protein and VEGF mRNA and protein was significantly decreased after embolization in the liposomal TAE-treated group compared with the TAE-treated group. The mean MVD significantly decreased at the invading edge of tumor margins and adjacent normal liver tissues in the liposomal curcumin TAE-treated group. This result suggested that the residual tumors and atypia tissues near normal liver tissues were blocked to get more blood supply and nutrition by angiogenesis. Meantime, the mean MVD has no significant difference between the liposomal curcumin TAE-treated group and the control group in Figure 8. Therefore, these results supported that liposomal curcumin may have effectively inhibited the HIF-1 $\alpha$ overexpression after embolization and hypoxia-induced angiogenesis in liver tumors.

In this study, the result of tumor size showed that the diameter of the tumor decreased in the liposomal curcumin TAE-treated group compared with the TAE-treated group on the third day after embolization, but the difference was not statistically significant. In addition, we observed that the tumor size slightly increased early within 24 hours after embolization. This phenomenon may be ascribed to acute edema after embolization and incomplete necrosis in the early stage. This study mainly explored that liposomal curcumin downregulated HIF-1 $\alpha$ protein levels and inhibited angiogenesis in early embolization stage. The long-time inhibitory effect will be discussed in a future study.

There are several limitations in this study. First, because this study was a pilot investigation to assess the effect of liposomal curcumin on HIF-1 $\alpha$ and angiogenesis in liver tumors after embolization, only one dose $(20 \mathrm{mg} / \mathrm{kg}$ body weight) of liposomal curcumin was used. Although the dose theoretically ensures the inhibition of HIF-1 $\alpha$, other doses of liposomal curcumin and the pharmacokinetics of the drug administered intraarterially should be the subject of future studies. Second, we only selected 6 hours, 24 hours, and 3 days after embolization as the sacrifice time points to ensure the short-time inhibitory effect of HIF- $1 \alpha$ and angiogenesis. The long-time inhibitory effect of liposomal curcumin including tumor size should be proved in future studies. Lastly, Ang 2 may be another HIF-1 $\alpha$ target, which is expressed on cancer cells and destabilizes the vascular integrity. In the future, we will explore Ang 2 expression and regulation of angiogenesis in hypoxia microenvironment after TAE. 
In conclusion, liposomal curcumin downregulates HIF-1 $\alpha$ protein levels and functional activity of angiogenesis and leads to the inhibition of its target, VEGF gene expression. Therefore, liposomal curcumin is an ideal inhibitor that can effectively block the hypoxia-induced angiogenesis after embolization in VX2 rabbit liver tumors. These findings suggest that embolization combined with adjuvant anti-HIF-1 $\alpha$ therapy is an ideal treatment method of residual tumors recurrence.

\section{Acknowledgments}

This work was supported by the Jiangsu Province Graduate Student Innovation Project (Grant CXLX13-591) and the Nanjing Medical Science and Technology Development Program (Grant YKK14156).

\section{Disclosure}

The authors report no conflicts of interest in this work. No benefits in any form have been received or will be received from a commercial party related directly or indirectly to the subject of this article.

\section{References}

1. Sherman M. Hepatocellular carcinoma: epidemiology, risk factors and screening. Semin Liver Dis. 2005;25(2):143-154.

2. Lllovet JM, Schwartz M, Mazzaferro V. Resection and liver transplantation for hepatocellular carcinoma. Semin Liver Dis. 2005;25(2):181-200.

3. Breedis C, Young G. The blood supply of neoplasms in the liver. Am J Pathol. 1954;30(5):969-977.

4. Brown DB, Gould JE, Gervais DA, et al. Transcatheter therapy for hepatic malignancy: standardization of terminology and reporting criteria. $J$ Vasc Interv Radiol. 2007;18(12):1469-1478.

5. Llovet JM, Real MI, Montaña X, et al; Barcelona Liver Cancer Group. Arterial embolization or chemoembolization versus symptomatic treatment in patients with unresectable hepatocellular carcinoma: a randomized controlled trial. Lancet. 2002;359(9319):1734-1739.

6. Semenza GL. HIF-1 and tumor progression: pathophysiology and therapeutics. Trends Mol Med. 2002;8(4):62-67.

7. Virmani S, Rhee TK, Ryu RK, Sato KT, Lewandowski RJ. Comparison of hypoxia-inducible factor-1 alpha expression before and after transcatheter arterial embolization in rabbit VX2 liver tumors. $J$ Vasc Inter Radiol. 2008;19(10):1483-1489.

8. Liang B, Zheng CS, Feng GS, et al. Correlation of hypoxia-inducible factor 1 alpha with angiogenesis in liver tumors after transcatheter arterial embolization in an animal mode 1. Cardivasc Intervent Radiol. 2010;33(4):806-812.

9. Shahneh FZ, Baradaran B, Zamani F, Aghebati-Maleki L. Tumor angiogenesis and anti-angiogenic therapies. Hum Antibodies. 2013;22(1-2): $15-19$.

OncoTargets and Therapy

\section{Publish your work in this journal}

OncoTargets and Therapy is an international, peer-reviewed, open access journal focusing on the pathological basis of all cancers, potential targets for therapy and treatment protocols employed to improve the management of cancer patients. The journal also focuses on the impact of management programs and new therapeutic agents and protocols on
10. Verheul HM, Pinedo HM. Possible molecular mechanisms involved in toxicity of angiogenesis inhibition. Nat Rev Cancer. 2007;7(6): $475-485$.

11. Jia ZZ, Jiang GM, Feng YL. Serum HIF-1 alpha and VEGF levels pre- and post-TACE in patients with primary liver cancer. Chin Med Sci J. 2011;26(3):158-162.

12. Bae MK, Kim SH, Jeong JW, et al. Curcumin inhibits hypoxia-induced angiogenesis via down-regulation of HIF-1. Oncol Rep. 2006;15(6): $1557-1562$.

13. Shehzad A, Lee J, Lee YS. Curcumin in various cancer. Biofactors. 2013;39(1):56-68.

14. Li L, Braiteh FS, Kurzrock R. Liposome-encapsulated curcumin: in vitro and in vivo effects on proliferation, apoptosis, signaling, and angiogenesis. Cancer. 2005;104(6):1322-1331.

15. Chen C, Johnston TD, Jeon $\mathrm{H}$, et al. An in vitro study of liposomal curcumin: stability, toxicity and biological activity in human lymphocytes and Epstein-Barr virus-transformed human B-cells. Int J Pharm. 2009;366(1-2):133-139.

16. Moreira PL, An YH. Animal models for therapeutic embolization. Cardiovasc Intervent Radiol. 2003;26(2):100-110.

17. Zhong H, De Marzo AM, Laughner E, et al. Overexpression of hypoxiainducible factor 1 in common human cancers and their metastases. Caner Res. 1999;59(22):5830-5835.

18. Yamaguchi R, Yano H, Lemura A, Ogasawara S, Haramaki M, Kojiro M. Expression of vascular endothelial growth factor in human hepatocellular carcinoma. Hepatology. 1998;28(1):68-77.

19. Weidner N, Semple JP, Welch WR, Folkman J. Tumor angiogenesis and metastasis-correlation in invasive breast carcinoma. N Engl J Med. 1991;324(1):1-8.

20. Bupathi M, Kaseb A, Janku F. Angiopoietin 2 as a therapeutic target in hepatocellular carcinoma treatment: current perspectives. Onco Targets Ther. 2014;7:1927-1932.

21. Yadaw VR, Aqqarwal BB. Curcumin: a component of the golden spice, targets multiple angiogenic pathways. Cancer Biol Ther. 2011;11(2): 236-241.

22. Bhandarkar SS, Arbiser JL. Curcumin as an inhibitor of angiogenesis. Adv Exp Med Biol. 2007;595:185-195.

23. Shan B, Schaaf C, Schmidt A, et al. Curcumin suppresess HIF1A synthesis and VEGF release in pituitary adenomas. J Endocrinol. 2012; 214(3):389-398.

24. Li L, Ahmed B, Mehta K, Kurzrock R. Liposomal curcumin with and without oxaliplatin: effects on cell growth, apoptosis, and angiogenesis in colorectal cancer. Mol Cancer Ther. 2007;6(4):1276-1282.

25. Mach CM, Mathew L, Mosley SA, Kurzrock R, Smith JA. Determination of minimum effective dose and optimal dosing schedule for liposomal curcumin in a xenograft human pancreatic cancer model. Anticancer Res. 2009;29(6):1895-1899.

26. Martin R, Geller D, Espat J, et al. Safety and efficacy of transarterial chemoembolization with drug-eluting beads in hepatocellular cancer: a systematic review. Hepatogastroenterology. 2012;59(113):255-260.

27. Rhee TK, Young JY, Larson AC, et al. Effect of transcatheter arterial embolization on levels of hypoxia-inducible factor-1 alpha in rabbit VX2 liver tumor. J Vasc Interv Radiol. 2007;18(5):639-645.

\section{Dovepress}

patient perspectives such as quality of life, adherence and satisfaction. The manuscript management system is completely online and includes a very quick and fair peer-review system, which is all easy to use. Visit http://www.dovepress.com/testimonials.php to read real quotes from published authors. 